\title{
Comparison of potato varieties between seasons and their potential for acrylamide formation
}

\author{
Bruno De Meulenaer, ${ }^{1 *}$ Tineke De Wilde, ${ }^{1}$ Frédéric Mestdagh, ${ }^{1}$ Yasmine Govaert, ${ }^{2}$ \\ Wilfried Ooghe, ${ }^{3}$ Stéphanie Fraselle, ${ }^{2}$ Kürt Demeulemeester, ${ }^{4}$ \\ Carlos Van Peteghem, ${ }^{3}$ André Calus, ${ }^{4}$ Jean-Marie Degroodt ${ }^{2}$ and Roland Verhé ${ }^{1}$ \\ ${ }^{1}$ Research Group Food Chemistry and Human Nutrition, Department of Food Safety and Food Quality, Faculty of Bioscience Engineering, \\ Ghent University, Coupure Links 653, B-9000 Ghent, Belgium \\ ${ }^{2}$ Scientific Institute of Public Health, Juliette Wytsmanstraat 14, B-1050 Brussels, Belgium \\ ${ }^{3}$ Laboratory of Food Analysis, Department of Bioanalysis, Faculty of Pharmaceutical Sciences, Ghent University, Harelbekestraat 72 , \\ B-9000 Ghent, Belgium \\ ${ }^{4}$ Interprovincial Research Institute for Potato Production, leperseweg 87, B-8800 Rumbeke-Beitem, Belgium
}

\begin{abstract}
BACKGROUND: Acrylamide is a probable human carcinogen produced during food preparation, including frying of potato products. The aim of this study was to investigate the impact of seasonal variation on tuber composition and its acrylamide generation potential.

RESULTS: The chemical composition of potato varieties used respectively for French fry (Bintje and Ramos) and crisp (Lady Rosetta and Saturna) production was studied throughout a storage period of 9 months during two growing seasons (2003 and 2004), in addition to their acrylamide generation potential during preparation of French fries. A significant impact of variable climatological conditions on the reducing sugar, dry matter, total free amino acid and free asparagine contents of tubers was observed. Exceptionally warm summers gave rise to a lower reducing sugar content (expressed on a dry matter basis) and thus a lower susceptibility to acrylamide generation during frying.
\end{abstract}

CONCLUSION: It cannot be excluded that potato growers and the potato-processing industry are confronted with some harvests that are more prone to acrylamide generation than others owing to climatological variability, thus confirming the importance of a multifactorial approach to mitigate acrylamide generation in potato products. (C) 2007 Society of Chemical Industry

Keywords: acrylamide; potato; variety; seasonal variation; reducing sugar

\section{INTRODUCTION}

The formation of acrylamide has been discovered by Swedish researchers in heated foods rich in starch, e.g. processed potato products such as chips (crisps) and French fries. ${ }^{1}$ Acrylamide is known to cause cancer in animals and has been classified by the WHO's International Agency on Cancer (IARC) as probably carcinogenic to humans. ${ }^{2}$

Soon after this discovery the main mechanism of formation of acrylamide in foods was clarified as a reaction between the free amino acid asparagine and reducing sugars (e.g. glucose and fructose) during frying, baking and roasting. ${ }^{3,4}$ Meanwhile, other precursors such as 3-aminopropionamide have been identified as well. ${ }^{5}$ Thus acrylamide occurs as a side product of the Maillard reaction, which provides appealing colour, odour and taste to many cooked foods.

Despite the fact that various technological approaches to mitigate acrylamide formation during frying of potato have already been described, ${ }^{6}$ raw material selection is considered to be of prime importance as well in order to develop a multifactorial strategy to reduce the acrylamide content of fried potato products. It has been confirmed by several authors ${ }^{7-12}$ that the content of reducing sugars in raw potato is well correlated with the amount of acrylamide formed upon heating. The reducing sugar content of potato tubers and therefore their acrylamide generation potency during frying may vary

* Correspondence to: Bruno De Meulenaer, Research Group Food Chemistry and Human Nutrition, Department of Food Safety and Food Quality, Faculty of Bioscience Engineering, Ghent University, Coupure Links 653, B-9000 Ghent, Belgium

E-mail: Bruno.Demeulenaer@UGent.be

Contract/grant sponsor: Belgian Federal Service of Public Health, Safety of the Food Chain and the Environment

(Received 6 December 2006; revised version received 5 June 2007; accepted 19 July 2007)

Published online 24 October 2007; DOI: 10.1002/jsfa.3091 
owing to various factors, including variety, ${ }^{7,12-14}$ storage conditions, ${ }^{11}$ fertilisation levels, ${ }^{15}$ calibre, ${ }^{14}$ etc. Apart from these factors, however, potato growers and the potato-processing industry are confronted by year-to-year variation in raw material characteristics.

Therefore the aim of this study was to investigate the impact of seasonal variation on tuber composition and its acrylamide generation potential. Four potato varieties grown in Flanders and harvested in 2003 (as reported previously by De Wilde et al. ${ }^{11}$ ) and 2004 were studied throughout a storage period of 9 months.

\section{MATERIALS AND METHODS Potato samples}

Varieties Bintje, Ramos, Saturna and Lady Rosetta were obtained from the Interprovincial Research Institute for Potato Production (Rumbeke-Beitem, Belgium). Growth conditions, apart from climatological influences, were similar in both growing seasons (e.g. soil, fertilisation, etc.). Climatological data from the measuring point closest to the test fields were obtained from the Royal Meteorological Institute (Ukkel, Belgium). After harvest in October each year, potatoes were stored for 9 months, and samples were taken in October, January, February, March, May and June. Potatoes were stored at $8{ }^{\circ} \mathrm{C}$ and treated with the sprout inhibitor CIPC (Chlorpropham, isopropyl- $\mathrm{N}$ (3-chlorophenyl)carbamate) at $1.5 \mathrm{~kg}$ Luxan-Grostop (13.4 $\mathrm{g} \mathrm{kg}^{-1}$ active substance) $\mathrm{t}^{-1}$ potatoes.

\section{Sample preparation and frying}

Potatoes for acrylamide determination were rinsed and fried as described previously. ${ }^{11,14}$ The frying process was identical (par-frying for $3 \mathrm{~min}$ at $180^{\circ} \mathrm{C}$, finish frying for $2 \mathrm{~min}$ at $180^{\circ} \mathrm{C}$ ), with the exception of the presence of a mixer in the oil used for frying potatoes harvested in 2004. By mixing the oil during heating, a more uniform oil temperature distribution was obtained and variability in acrylamide levels was reduced. ${ }^{16}$ The remaining raw potatoes were cut into small cubes and kept at $-18^{\circ} \mathrm{C}$ prior to analysis of their chemical composition.

\section{Reagents and chemicals}

The reagents and chemicals used in the following chemical analyses were the same as those described previously. ${ }^{11}$ All analyses were performed in duplicate.

\section{Chemical characterisation of potatoes}

Dry matter (DM) content

The determination of DM content was based on AOAC method $930.15 .{ }^{17}$ Briefly, $5 \mathrm{~g}$ of homogenised raw potato was mixed with calcined sea sand and heated in an oven at $105^{\circ} \mathrm{C}$ until constant weight was obtained.

\section{Crude protein content}

Total Kjeldahl protein content was determined according to Egan et al. ${ }^{18}$ About $2 \mathrm{~g}$ of homogenised raw potato was placed in a Kjeldahl tube, then $10 \mathrm{~mL}$ of $\mathrm{H}_{2} \mathrm{SO}_{4}$ and one Kjeltab CX tablet (catalyst compound) were added. The decomposition was done in a destruction block $\left(420^{\circ} \mathrm{C}\right)$ until a clear solution was obtained. Distillation was carried out with a 2200 Kjeltec Auto (FOSS Tecator, Hillerød, Denmark Sweden). The obtained distillate was titrated with $0.05 \mathrm{~mol} \mathrm{~L}^{-1} \mathrm{HCl}$. For the calculation of crude protein content a conversion factor of 6.25 was used.

\section{Free amino acid content}

Mixed raw potatoes $(15 \mathrm{~g})$ were placed in a $100 \mathrm{~mL}$ quantitative flask and diluted to $100 \mathrm{~mL}$ with $150 \mathrm{~mL}$ $\mathrm{L}^{-1}$ trichloroacetic acid (TCA). After incubation (10 min at ambient temperature) and filtration the filtrate was diluted in injection buffer and injected into a Biotronik LC3000 amino acid analyser (Biotronik, Hanau, Germany) as described previously. ${ }^{11}$

\section{Sugars}

After aqueous extraction from homogenised raw potato, mono- and disaccharides were determined by gas chromatographic analysis with the addition of an internal standard. After filtration and evaporation a derivatisation step was carried out. Analyses were performed using a Varian 3380 gas chromatograph equipped with a flame ionisation detector (Varian Instrument Group, Walnut Creek, CA, USA) as described previously. ${ }^{11}$

\section{Acrylamide}

The determination of acrylamide was carried out using an accredited method based on the standard ISO 17025 with minor modifications, as described previously. ${ }^{11}$ Acrylamide was extracted from the foodstuff with water before the clean-up step. Further concentration by evaporation was carried out before analysis by liquid chromatography/tandem mass spectrometry (LC/MS/MS). Acrylamide was quantified by interpolation from a linear calibration curve based on standard solutions over a concentration range from 0 to $1000 \mu \mathrm{g} \mathrm{kg}^{-1}$, using 2,3,3-[D3]acrylamide (daughter ion $\mathrm{m} / \mathrm{z} 75>58$ ) as internal standard for recovery correction. The limits of the method are 10 and $20 \mu \mathrm{g}$ acrylamide $\mathrm{kg}^{-1}$ foodstuff for detection and quantification respectively. ${ }^{19}$

\section{Statistical analysis}

Statistical analysis of the data was performed using SPSS Version 12.0 (SPSS Inc., Chicago, IL, USA). Univariate analysis (general linear model) was performed to determine significant influences $(P \leq 0.05)$ of parameters (i.e. variety, storage time and year) on intrinsic factors (i.e. DM content, reducing sugar content, etc.). Post hoc comparison of means (Duncan's multiple range test) was carried out to determine significant differences between the different levels within each treatment. The term 'significant' is used to indicate differences for which $P \leq 0.05$. 


\section{RESULTS AND DISCUSSION}

\section{Seasonal conditions}

The average monthly temperature profile at the growing site is shown in Fig. 1 . The climatic conditions during 2003 were considered as exceptional. The summer of 2003 was remarkably hot. Average temperatures were higher than normal for almost the entire growing season. Moreover, Belgium was struck by a heat wave that lasted for 14 days (31 July-13 August 2003). The summer of 2004 was also characterised by abnormally high temperatures, but overall it was not considered as exceptional.

The average monthly precipitation profile at the growing site is shown in Fig. 2. The volume of precipitation in 2003 was normal, as it also was in the spring of 2004. However, an extreme peak was reached in August 2004.

\section{Reducing sugars}

The reducing sugar (glucose and fructose) content of potatoes harvested in 2003 and 2004 as a function of storage time is shown in Fig. 3. Data on the initial reducing sugar content of Lady Rosetta were

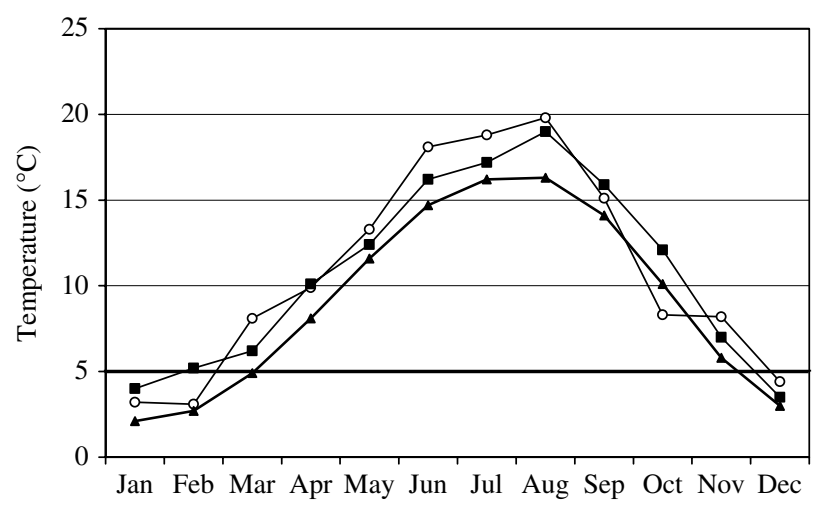

Figure 1. Average monthly temperature in 2003 (O) and 2004 (D) plotted against standard values ( $\boldsymbol{\Lambda}$, long-year average).

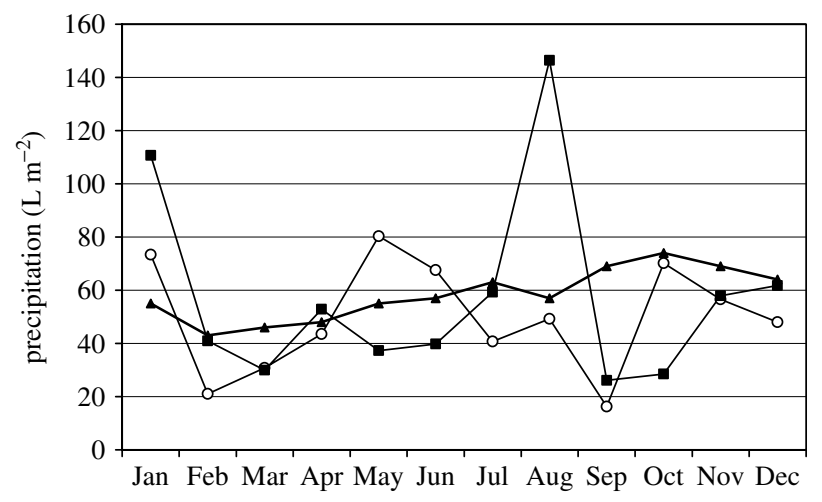

Figure 2. Average monthly precipitation in 2003 (O) and 2004 (口) plotted against standard values $(\boldsymbol{\Lambda}$, long year average).

not available. Potatoes harvested in 2004 showed a significantly higher reducing sugar content throughout the whole storage period, with the exception of Lady Rosetta in month 4 and Saturna in month 1. Similarly to 2003, the reducing sugar content of Bintje, Ramos and Saturna tubers did not change significantly as a function of storage time. Lady Rosetta tubers from the 2004 harvest, on the other hand, seemed to be liable to senescent sweetening, whereas the tubers from 2003 were not.

These differences between the two growing seasons may be explained by the different climatological conditions throughout the respective years. Because of the higher temperatures in 2003, it seems likely that the tubers reached their full maturity earlier than in 2004, giving rise to a lower sugar content. ${ }^{14}$ In addition, the extreme rainfall at the end of the growing season in 2004 may have contributed to an increase in the reducing sugar content of these tubers. This is in accordance with Davies et al. ${ }^{20}$ who stated that drought lowered the reducing sugar level. With regard to the higher susceptibility of Lady Rosetta tubers to senescent sweetening in 2004, it could be noted that this phenomenon is typically associated with a season

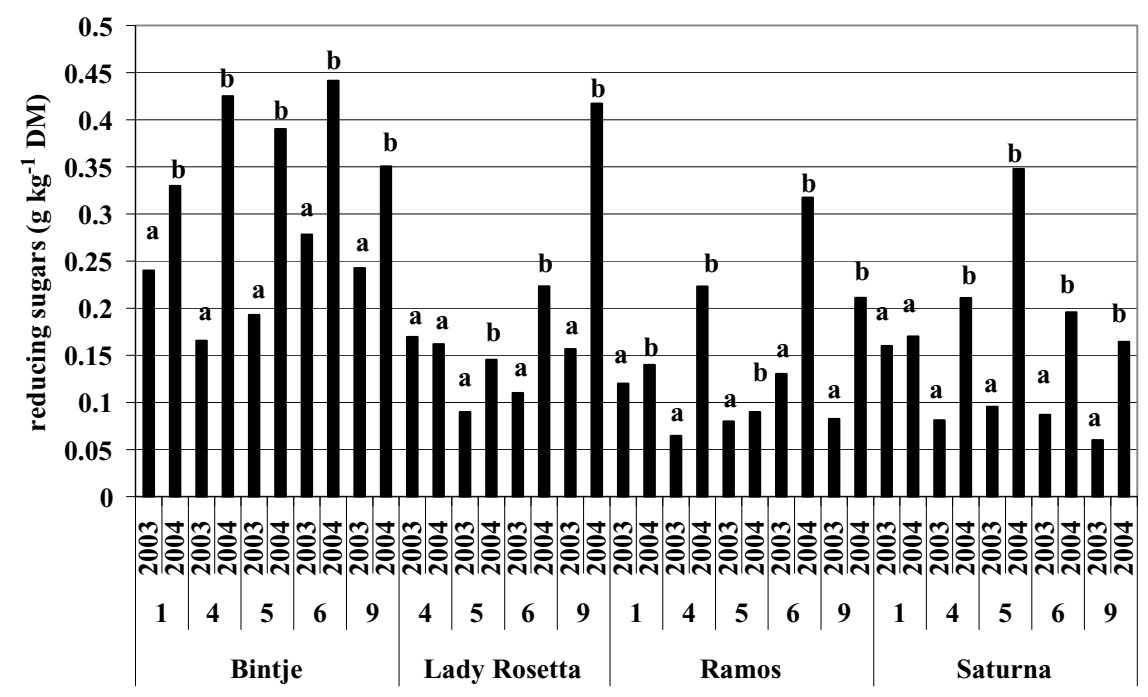

Figure 3. Concentrations of reducing sugars in different potato cultivars from 2003 and 2004 harvests stored for $0,4,5,6$ and 9 months at $8{ }^{\circ} \mathrm{C}$. Different letters per variety and per month indicate significant differences $(P \leq 0.05)$. 
Table 1. Seasonal influence on dry matter (DM), crude protein, total free amino acid, free asparagine and sucrose contents of four potato cultivars

\begin{tabular}{lcccccc}
\hline Variety & Year & $\begin{array}{c}\text { Dry matter } \\
\left(\mathrm{g} \mathrm{kg}^{-1}\right)\end{array}$ & $\begin{array}{c}\text { Crude protein } \\
\left(\mathrm{g} \mathrm{kg}^{-1} \mathrm{DM}\right)\end{array}$ & $\begin{array}{c}\text { Total free amino } \\
\text { acids }\left(\mathrm{g} \mathrm{kg}^{-1} \mathrm{DM}\right)\end{array}$ & $\begin{array}{c}\text { Free asparagine } \\
\left(\mathrm{g} \mathrm{kg}^{-1} \mathrm{DM}\right)\end{array}$ & $\begin{array}{c}\text { Sucrose } \\
(\mathrm{g} \mathrm{kg}\end{array}$ \\
\hline Bintje & 2003 & $23.50 \mathrm{a}$ & $10.77 \mathrm{a}$ & $3.56 \mathrm{a})$ & $1.24 \mathrm{a}$ & $0.61 \mathrm{a}$ \\
Lady Rosetta & 2004 & $20.89 \mathrm{~b}$ & $11.00 \mathrm{a}$ & $4.33 \mathrm{~b}$ & $1.75 \mathrm{~b}$ & $0.74 \mathrm{a}$ \\
& 2003 & $27.18 \mathrm{a}$ & $10.18 \mathrm{a}$ & $2.21 \mathrm{a}$ & $0.85 \mathrm{a}$ & $0.81 \mathrm{a}$ \\
Ramos & 2004 & $24.25 \mathrm{~b}$ & $11.53 \mathrm{a}$ & $3.15 \mathrm{~b}$ & $1.22 \mathrm{~b}$ & $0.75 \mathrm{a}$ \\
& 2003 & $24.44 \mathrm{a}$ & $9.91 \mathrm{a}$ & $3.77 \mathrm{a}$ & $1.51 \mathrm{a}$ & $0.58 \mathrm{a}$ \\
Saturna & 2004 & $21.59 \mathrm{~b}$ & $11.15 \mathrm{a}$ & $4.77 \mathrm{~b}$ & $2.02 \mathrm{~b}$ & $0.70 \mathrm{a}$ \\
& 2003 & $26.52 \mathrm{a}$ & $10.06 \mathrm{a}$ & $2.80 \mathrm{a}$ & $1.38 \mathrm{a}$ & $0.67 \mathrm{a}$ \\
\hline
\end{tabular}

Values represent the average of all measurements performed during storage for 9 months at $8{ }^{\circ} \mathrm{C}$. Different letters per variety indicate significant differences $(P \leq 0.05)$.

characterised by a short dormancy period. However, it could not be assessed whether the exceptional climatological conditions in 2003 led to significantly faster sprouting of the tubers in 2004. Moreover, it should be noted that the beginning of senescent sweetening throughout storage can be influenced by multiple factors such as storage temperature, storage period, genotype, soil and environmental conditions. ${ }^{21}$ Therefore it is difficult to draw general conclusions with regard to this particular phenomenon.

\section{Sucrose}

The average sucrose content of potatoes grown in 2003 and 2004 is presented in Table 1 . Since the sucrose content did not vary during storage time in both years (results not shown), the average value for each variety and season was used to statistically evaluate the differences between the two seasons. From this it was concluded that, despite the climatological differences between the two years, no significant differences in the sucrose content of tubers could be observed within the same variety. This is in contrast to the differences observed in the reducing sugar content (Fig. 3).

\section{Dry matter}

Similarly, the dry matter content did not vary significantly throughout the storage period (results not shown). It was significantly higher in tubers harvested in 2003 than in those harvested in 2004 (Table 1). This was probably due to the higher rainfall at the end of the growing season in 2004 leading to a higher soil moisture content and provoking a decrease in the dry matter content of tubers.

\section{Nitrogen compounds}

The crude protein, total free amino acid and asparagine contents did not vary significantly as a function of storage time (results not shown). This is in agreement with a more extended storage study on several varieties conducted in our laboratories. ${ }^{14}$ The crude protein content of tubers harvested in 2004 appeared to be higher but not significantly different from that of tubers harvested in 2003 for all varieties studied (Table 1 ). The average free amino acid content, however, was significantly higher in potatoes harvested in 2004 compared with those harvested in 2003. Likewise, the free asparagine content was observed to be significantly higher for all varieties in 2004. Because the total free amino acid content is influenced by the available amount of nitrogen fertiliser, ${ }^{15}$ it is possible that, owing to the exceptional heat and drought that occurred in 2003, the potatoes did not absorb the same amount of fertiliser during growth.

\section{Acrylamide formation}

Acrylamide formation was evaluated for all samples studied after the preparation of French fries (Fig. 4). A similar trend to that of the reducing sugar content of tubers (Fig. 3) was noted, confirming the previously observed correlation between the reducing sugar content of tubers and their potential for acrylamide generation during frying. ${ }^{11}$ Apart from a few exceptions, tubers harvested in 2004 showed a higher capacity to generate acrylamide during frying throughout the whole storage period for all varieties studied. In several cases the amount of acrylamide generated was even doubled as a result of the seasonal variability in tuber composition (Bintje at 9 months of storage, Lady Rosetta and Ramos at 6 months and Saturna at 5 months). Comparing the results presented in Figs 3 and 4, however, it could also be observed that there was no proportional relationship between the seasonally dependent fluctuation in reducing sugar content of tubers and the seasonally dependent change in the amount of acrylamide generated during frying. Considering the reducing sugar content for Bintje tubers, for instance, after 4 months of storage it can be seen that potatoes harvested in 2004 contained nearly twice the amount of reducing sugars as those harvested in 2003. Nevertheless, this considerable increase in reducing sugar content resulted in a limited increase in acrylamide generation during frying. This observation suggests that, apart from seasonal fluctuations in reducing sugar content, other compositional parameters exerting an influence on the complex mechanism of acrylamide generation may also be influenced by seasonal variability. Changes in the net content of free amino acids neither could be correlated with the observed results. It is possible 


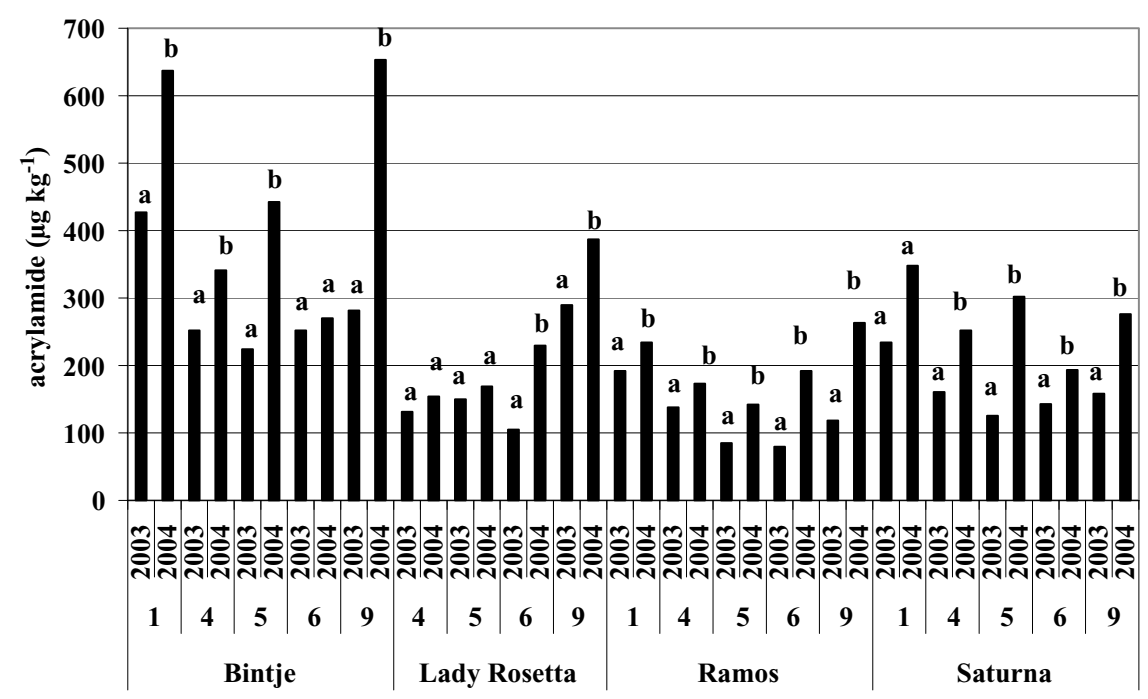

Figure 4. Acrylamide contents after frying of different potato cultivars from 2003 and 2004 harvests stored for $0,4,5,6$ and 9 months at $8{ }^{\circ} \mathrm{C}$. Different letters per variety and per month indicate significant differences $(P \leq 0.05)$.

that the content of other precursors such as 3aminopropionamide, ${ }^{5}$ which had not been identified when this study was conducted, could also be influenced by seasonal variability.

\section{CONCLUSION}

It has been demonstrated in this study that, owing to variations in climatological conditions between seasons, year-to-year variability in the susceptibility of potato tubers to acrylamide generation during frying can also be expected. This variability may be due to a change in tuber composition at harvest or to a change in the susceptibility of tubers to senescent sweetening. Consequently, it cannot be excluded that potato growers and the potato-processing industry are confronted with some harvests that are more prone to acrylamide generation then others. This underlines the importance of a multifactorial approach to mitigate acrylamide generation in potato products.

\section{ACKNOWLEDGEMENT}

This research was financed by the Belgian Federal Service of Public Health, Safety of the Food Chain and the Environment.

\section{REFERENCES}

1 Tareke E, Rydberg P, Karlsson P, Eriksson S and Törnqvist M, Analysis of acrylamide, a carcinogen formed in heated foodstuffs. F Agric Food Chem 50:4998-5006 (2002).

2 IARC, Some Industrial Chemicals, Vol. 60 of Monographs on the Evaluation of Carcinogenic Risks to Humans. International Agency for Research on Cancer, Lyon, pp. 389-443 (1994).

3 Mottram DS, Wedzicha BL and Dodson AT, Acrylamide is formed in the Maillard reaction. Nature 419:448-449 (2002).

4 Stadler RH, Blank I, Varga N, Robert F, Hau J, Guy PA, et al, Acrylamide from Maillard reaction products. Nature 419:449-450 (2002).

5 Granvogl M, Jezussek M, Koehler P and Schieberle P, Quantitation of 3-aminopropionamide in potatoes $-\mathrm{a}$ minor but potent precursor in acrylamide formation. I Agric Food Chem 52:4751-4757 (2004).

6 Stadler RH and Scholz G, Acrylamide: an update on current knowledge in analysis, levels in food, mechanisms of formation, and potential strategies of control. Nutr Rev 62:449-467 (2004).

7 Amrein TM, Bachmann S, Noti A, Biedermann M, Barbosa MF, Biedermann-Brem S, et al, Potential of acrylamide formation, sugars, and free asparagine in potatoes: a comparison of cultivars and farming systems. F Agric Food Chem 51:5556-5560 (2003).

8 Becalski A, Lau BPY, Lewis D, Seaman SW, Hayward S, Sahagian $\mathrm{M}$, et al, Acrylamide in French fries: influence of free amino acids and sugars. F Agric Food Chem 52:3801-3806 (2004).

9 Chuda Y, Ono H, Yada H, Ohara-Takada A, MatsuuraEndo C and Mori M, Effects of physiological changes in potato tubers (Solanum tuberosum L.) after low temperature storage on the level of acrylamide formed in potato chips. Biosci Biotechnol Biochem 67:1188-1190 (2003).

10 Matthäus B, Haase NU and Vosmann K, Factors affecting the concentration of acrylamide during deep-fat frying of potatoes. Eur F Lipid Sci Technol 106:793-801 (2004).

11 De Wilde T, De Meulenaer B, Mestdagh F, Govaert Y, Vandeburie $\mathrm{S}$, Ooghe $\mathrm{W}$, et al, Influence of storage practices on acrylamide formation during frying. 7 Agric Food Chem 53:6550-6557 (2005).

12 Williams JSE, Influence of variety and processing conditions on acrylamide levels in fried potato crisps. Food Chem 90:875-881 (2005).

13 Olsson K, Svensson R and Roslund CA, Tuber components affecting acrylamide formation and colour in fried potato: variation by variety, year, storage temperature and storage time. F Sci Food Agric 84:447-458 (2004).

14 De Wilde T, De Meulenaer B, Mestdagh F, Govaert Y, Ooghe W, Fraselle S, et al, Selection criteria for potato tubers to minimize acrylamide formation during frying. $\mathcal{F}$ Agric Food Chem 54:2199-2205 (2006).

15 De Wilde T, De Meulenaer B, Mestdagh F, Govaert Y, Vandeburie $\mathrm{S}$, Ooghe W, et al, Influence of fertilization and haulm killing on acrylamide formation during potato frying. $\mathcal{F}$ Agric Food Chem 54:404-408 (2006).

16 Mestdagh F, De Meulenaer B, Van Poucke C, Detavernier C, Cromphout $\mathrm{C}$ and Van Peteghem C, Influence of oil type on the amounts of acrylamide generated in a model system and French fries. I Agric Food Chem 53:6170-6174 (2006).

17 AOAC, Official Methods of Analysis (15th edn). Association of Official Analytical Chemists, Arlington, VA, p. 69 (1990). 
18 Egan H, Kirk R and Sawyer R, Pearson's Chemical Analysis of Foods (8th edn). Churchill Livingstone, Edinburgh, pp. 66-71 (1981).

19 Govaert Y, Arisseto A, Van Loco J, Fraselle S, Weverbergh E, Degroodt JM, et al, Optimisation of a liquid chromatography-tandem mass spectrometric method for the determination of acrylamide in foods. Anal Chim Acta 556:275-280 (2006).
20 Davies HV, Jefferies RA and Scobie L, Hexose accumulation in cold-stored tubers of potato (Solanum tuberosum L.) - the effects of water-stress. F Plant Physiol 134:471-475 (1989).

21 Isherwood FA and Burton WG, The effect of senescence, handling, sprouting and chemical sprouting suppression upon the respiratory quotient of stored potato tubers. Potato Res 18:98-104 (1976) 